\title{
CDISC SDTM Respiratory Test Name Terminology
}

National Cancer Institute

\section{Source}

National Cancer Institute. CDISC SDTM Respiratory Test Name Terminology. NCI

Thesaurus. Code C111107.

Terminology associated with the respiratory test name codelist of the Clinical Data Interchange Standards Consortium (CDISC) Study Data T abulation Model (SDT M). 